\title{
Scaling power and bandwidth of mid-infrared supercontinuum source based on a GeO2 doped silica fiber
}

Jain, Deepak; Raghuraman, Sidharthan; Bowen, Patrick; Moselund, Peter M.; Yoo, Seongwoo; Bang, Ole

Published in:

Proceedings of SPIE

Link to article, DOI:

$10.1117 / 12.2509291$

Publication date:

2019

Document Version

Publisher's PDF, also known as Version of record

Link back to DTU Orbit

Citation (APA):

Jain, D., Raghuraman, S., Bowen, P., Moselund, P. M., Yoo, S., \& Bang, O. (2019). Scaling power and bandwidth of mid-infrared supercontinuum source based on a GeO2 doped silica fiber. In Proceedings of SPIE (Vol. 10897). [108970U] SPIE - International Society for Optical Engineering. Proceedings of SPIE - The International Society for Optical Engineering https://doi.org/10.1117/12.2509291

\section{General rights}

Copyright and moral rights for the publications made accessible in the public portal are retained by the authors and/or other copyright owners and it is a condition of accessing publications that users recognise and abide by the legal requirements associated with these rights.

- Users may download and print one copy of any publication from the public portal for the purpose of private study or research.

- You may not further distribute the material or use it for any profit-making activity or commercial gain

- You may freely distribute the URL identifying the publication in the public portal 


\section{Scaling power and bandwidth of mid- infrared supercontinuum source based on a GeO2 doped silica fiber}

Deepak Jain, Sidharthan Raghuraman, Patrick Bowen, Peter M. Moselund, Seongwoo Yoo, et al.

Deepak Jain, Sidharthan Raghuraman, Patrick Bowen, Peter M. Moselund, Seongwoo Yoo, Ole Bang, "Scaling power and bandwidth of mid-infrared supercontinuum source based on a $\mathrm{GeO} 2$ doped silica fiber

," Proc. SPIE 10897, Fiber Lasers XVI: Technology and Systems, 108970 U (7 March 2019); doi: 10.1117/12.2509291

SPIE. Event: SPIE LASE, 2019, San Francisco, California, United States 


\title{
Scaling power and bandwidth of mid-infrared supercontinuum source based on a $\mathrm{GeO} 2$ doped silica fiber
}

\section{DEEPAK JAIN ${ }^{1},{ }^{4 *}$, RAGHURAMAN SIDHARTHAN $^{2}$, PATRICK BOWEN $^{3}$, PETER M. $^{2}$ MOSELUND $^{3}$, SEONGWOO YOO ${ }^{2}$, AND OLE BANG ${ }^{1,3}$}

\author{
1. DTU Fotonik, Department of Photonics Engineering, Technical University of Denmark, Lyngby, Denmark \\ 2. Center for Optical Fiber Technology, The Photonics Institute, Nanyang Technological University, \\ Singapore \\ 3. NKT Photonics A/S, Blokken 84, Birkerød, Denmark \\ 4. Currently at School of Physics, University of Sydney, Sydney, NSW, Australia
}

\begin{abstract}
We demonstrate a $70 \mathrm{~mol} \% \mathrm{GeO}_{2}$ doped fiber for mid-infrared supercontinuum generation. Experiments ensure a highest output power for a broadest spectrum from $1000 \mathrm{~nm}$ to $3000 \mathrm{~nm}$ from this fiber, while being pumped by a broadband 4 stage Erbium fiber based MOPA. Our investigations reveal the unexploited potential of Germania doped fiber for mid-infrared supercontinuum generation. To the best of our knowledge, this is the record power, for an ultrabroadband, all-fiberized, and compact device size supercontinuum light source based on Silica and Germania fiber, ever demonstrated to the date.
\end{abstract}

Keywords: Fiber amplifiers, Large mode area fibers, Er-doped fibers, High power lasers.

\section{INTRODUCTION}

Supercontinuum (SC) sources emitting in mid-infrared (Mid-IR) wavelength region are of great importance because this region offers unique opportunities of spectroscopy, imaging, monitoring of several molecular species and gases. The silica-based fibers are limited up to $2.4 \mu \mathrm{m}$ due to high phonon energy of silica glass. Another alternative option for further broadening is Germania $\left(\mathrm{GeO}_{2}\right)$ based glass [1]. Recently, we demonstrated a $1.44 \mathrm{~W}$ output power for a broadest spectrum from $700 \mathrm{~nm}$ to $3200 \mathrm{~nm}$ wavelength region [2]. Yin et al. demonstrated a SC source emitting a $20 \mathrm{~dB}$ spectrum from $1944 \mathrm{~nm}$ to $3450 \mathrm{~nm}$ using a $20 \mathrm{~dB}$ input spectrum spanning from $1965 \mathrm{~nm}$ to $2666 \mathrm{~nm}$ produced by a cascaded source of a TDFA and a 1.9-2.7 $\mu \mathrm{m}$ SC laser source. The germania fiber had a core diameter of $3.5 \mu \mathrm{m}$. In order to further scale the output power, Yin et al. used a $8 \mu \mathrm{m}$ core fiber, however this resulted into lower non-linearity and required an input power of $40 \mathrm{~W}$ from thulium doped fiber amplifier to reach $3000 \mathrm{~nm}$ [4]. This resulted into a system not suitable for many applications where a low average power source between 2 to $3 \mu \mathrm{m}$ is required to avoid the damage to samples such as imaging and monitoring etc.

In this report, we report a $9 \mu \mathrm{m}$ core diameter fiber which is being pumped by a broadband 4-stage Er-Yb fiber based master oscillator power amplifier (MOPA). In order to further extend the input spectrum of MOPA, we use a piece of Tm-doped fiber as a red-shifter. We demonstrate a $20 \mathrm{~dB}$ supercontinuum from $1 \mu \mathrm{m}$ to $3 \mu \mathrm{m}$ with output power exceeding $5 \mathrm{~W}$, to the best of our knowledge, this is the broadest spectrum ever generated with high power exceeding 1.4 $\mathrm{W}$ level from a $\mathrm{GeO} 2$ doped fiber. On the other hand, we also produce spectrum spanning from $1.7 \mu \mathrm{m}$ to $3.4 \mu \mathrm{m}$ at ultralow power such as $10 \mathrm{~s}$ of mw with more than $50 \%$ power fraction above $2400 \mathrm{~nm}$ wavelength region. This makes these sources suitable for several application where broadband sources at low power are required to avoid the damage of samples.

*deepakjain9060@gmail.com; phone+61 451159656; fotonik.dtu.dk

Fiber Lasers XVI: Technology and Systems, edited by Adrian L. Carter, Proc. of SPIE Vol. 10897, $108970 \mathrm{U} \cdot$ (c) 2019 SPIE · CCC code: 0277-786X/19/\$18 · doi: 10.1117/12.2509291 


\section{PUMP SOURCE AND GeO2 DOPED FIBER}

An all-fiberized compact 4-stage MOPA was constructed in-house, a diode laser being directly modulated was used as a seed source. The pulse width was fixed to $1 \mathrm{~ns}(+/-100 \mathrm{ps})$ and frequency could be varied from $10 \mathrm{KHz}$ to $20 \mathrm{MHz}$. The signal was further amplified in 3 stages. Figure 1(a) shows the pump power of final stage and final output power with respect to the pump current. A highest power of $13.17 \mathrm{~W}$ was obtained at $34 \mathrm{~W}$ of pump power with a nearly $40 \%$ slope efficiency. Figure 1(b) shows the output spectrum for three different pump currents $1 \mathrm{~A}, 4 \mathrm{~A}$, and 8 A corresponding to $0.53 \mathrm{~W}, 6.39 \mathrm{~W}$, and $13.17 \mathrm{~W}$ output power respectively. A heavily Germania doped silica fiber with $9 \mu \mathrm{m}$ core diameter, with $\mathrm{GeO}_{2}$ molar concentration of around $70 \%$ was used in this work. This fiber was fabricated using optimized modified chemical vapor deposition (MCVD) process at COFT, NTU Singapore. Figure 1(c) shows the schematic of the SC source where the delivery of pump source is spliced to GeO2-doped fiber either directly or via a Tm-doped fiber, the output end of fiber was cleaved to 8 degree.
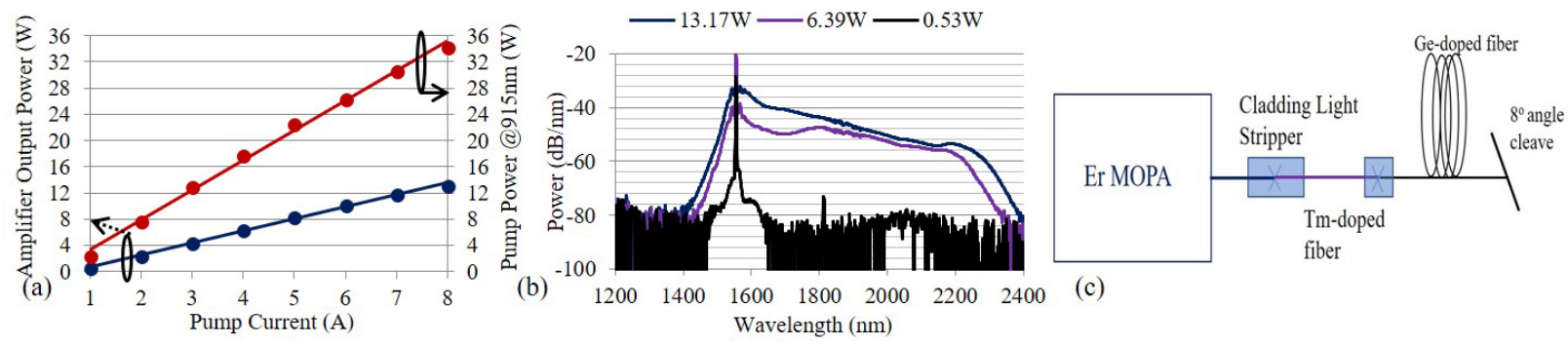

Figure 1(a) Output power and pump power with respect to pump current for a 4-stage Er-fiber based MOPA at 10MHz rep rate (b) output spectrum of Er-MOPA at different output power at $10 \mathrm{MHz}$ rep rate and (c) schematic of SC source.

\section{SUPERCONTINUUM EXPERIMENTS}
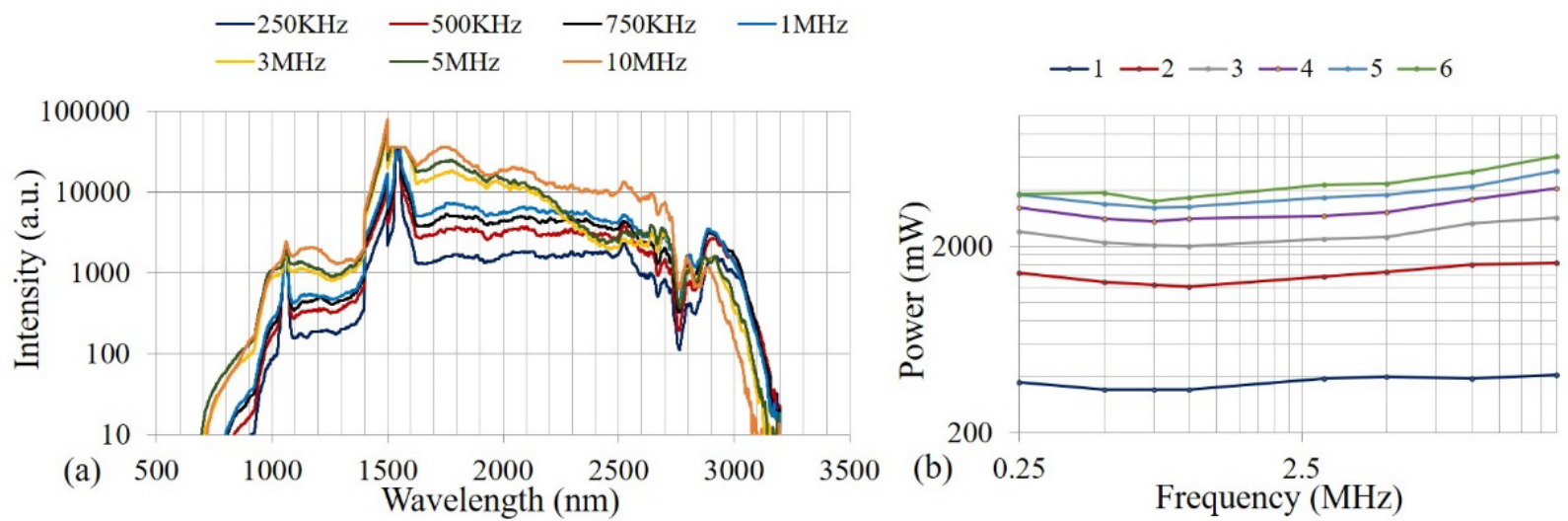

Fig. 2(a) Output spectrum of SC source at 6A pump current (corresponding to output power $8 \mathrm{~W}$ at $10 \mathrm{MHz}$ rep rate) for different rep rates (b) Output power for different rep rates and pump currents. 
Figure 2(a) shows the SC spectra obtained for different repetition rate of seed diode of the MOPA at 6A current. Figure 2(b) shows the output power for different rep rates and currents. The length of the fiber is approximately $25 \mathrm{~cm}$, several cutbacks were made to reach to this optimum length. A $20 \mathrm{~dB}$ bandwidth from $\sim 1000 \mathrm{~nm}$ to $\sim 3000 \mathrm{~nm}$ can be achieved. The output power up to $6 \mathrm{~W}$ at higher rep rates can be achieved. The optimum frequency for broadening is $3 \mathrm{MHz}$, as there is a trade-off between higher rep rate and peak power. The output power is limited just because of the available input power. To the best of our knowledge, this is best performance of a $\mathrm{GeO} 2$ doped for SC generation. In other set of experiments, we spliced a piece of highly $\mathrm{Tm}_{2} \mathrm{O}_{3}$ doped fiber to the pigtail fiber of MOPA in order to extend the spectrum, now spectrum reaches up to around $\sim 2800 \mathrm{~nm}$. Figure 3 (a) shows the spectra of a $40 \mathrm{~cm}$ long $\operatorname{Tm}_{2} \mathrm{O}_{3}$ doped fiber and $13.5 \mathrm{~cm}$ long $\mathrm{GeO}_{2}$ doped fiber at different rep rates at $2 \mathrm{~A}$, we optimized the length of both fibers using cutback method. The red edge for 10 and $20 \mathrm{~dB}$ bandwidth is approximately $3200 \mathrm{~nm}$ and $3300 \mathrm{~nm}$ respectively and the blue edge is around $1800 \mathrm{~nm}$. The spectra look fairly flat other than absorption peak around $2700 \mathrm{~nm}$. Figure 3(b) shows the spectra at fixed rep rate of $1 \mathrm{MHz}$ for different currents, it is interesting to note that, even at very low current such as 1A (output power of SC is $\sim 16 \mathrm{~mW}$ and power above $2400 \mathrm{~nm}$ is $\sim 8 \mathrm{~mW}$ ), the $10 \mathrm{~dB}$ bandwidth is $1900 \mathrm{~nm}$ to $3000 \mathrm{~nm}$. This is extremely important of several applications, where a broadband source is required at low power so that damages to the samples under test can be avoided. To the best of our knowledge, this is the first report showing such remarkable (broadband-high power and broadband-low power) SC sources.
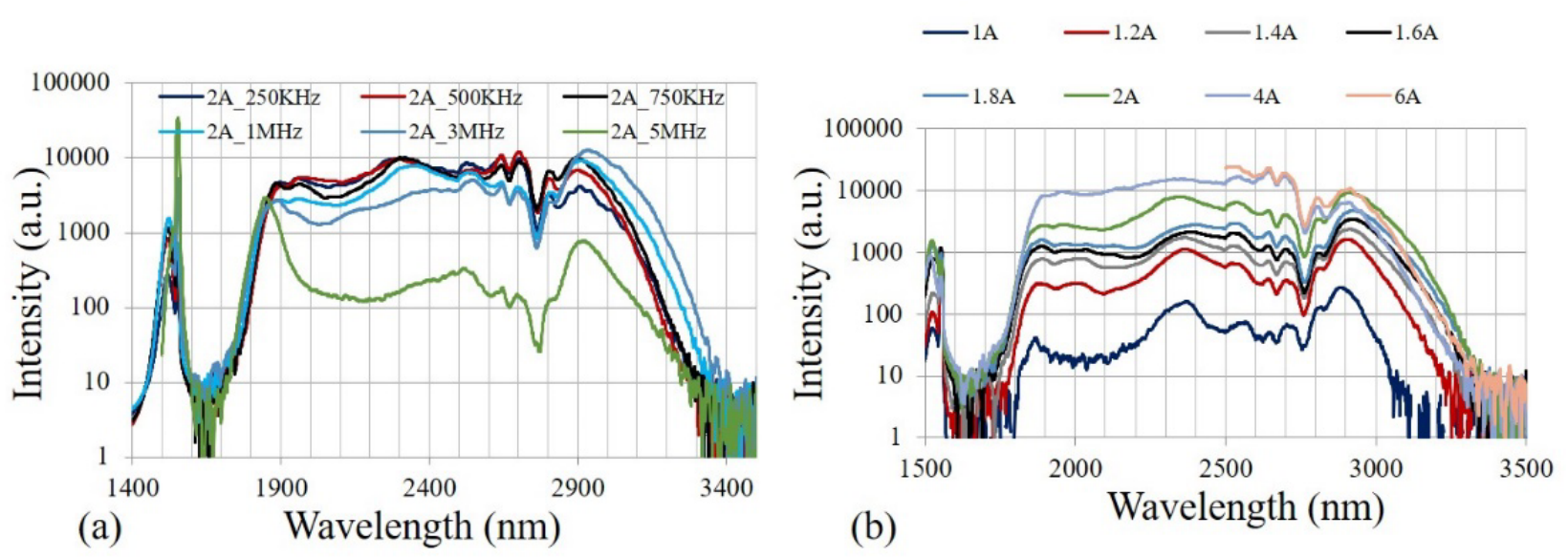

Fig. 3(a) Output spectra of SC source at (a) 2A pump current for different rep rates (b) $1 \mathrm{MHz}$ rep rate for different currents.

\section{CONCLUSION}

We demonstrate highest output power for a broadest supercontinuum source based on Silica and Germania fiber in an all fiberized and compact size device. Our investigations reveal the unexploited potential of Germania doped fiber for midinfrared supercontinuum generation and surpasses the current state-of-the-art results.

\section{ACKNOWLEDGEMENT}

D. J. acknowledges the support from Hans Christian Ørsted COFUNDED Marie-curie action fellowship. The authors acknowledge financial support from Innovation Fund Denmark for the project ShapeOCT (J. No. 4107-00011A). S.Y acknowledges A*STAR's support through Advanced Optics Engineering programme. 


\section{REFERENCES}

[1] Dianov et al., "Germania-based core optical fibers," J. Lightwave. Technol., 23(11), 3500-3508 (2005).

[2] D Jain et al., "Record power, ultra-broadband supercontinuum source based on highly GeO2 doped silica fiber," Opt. Exp. 24(23), 26667-26677 (2016).

[3] K Yin et al., "1.9-3.6 $\mu \mathrm{m}$ supercontinuum generation in a very short highly-nonlinear germanium fiber with a high mid-infrared power ratio," Opt. Lett. 41, 5067-5070 (2016).

[4] K Yin et al., "30 W monolithic 2-3 $\mu \mathrm{m}$ supercontinuum laser," Photonics Research, 6, 123-126 (2018). 